\title{
Differing perceptions in the feedback process
}

DAVID CARLESS

University of Hong Kong

Studies in Higher Education, 31(2), 219-233.

ABSTRACT Feedback is central to the development of effective learning, yet is comparatively under-researched. This paper seeks to examine the notion of written feedback on assignments and argue that this feedback process is more complex than is sometimes acknowledged. I illustrate the problematic nature of assignment feedback by drawing on a large-scale questionnaire survey conducted across eight universities and then analysing the issue in more depth though fine-grained data collected from students in a teacher education institute. The paper is framed by the concepts of discourse, power and emotion. It highlights a number of different perceptions of students and tutors towards the assessment, marking and feedback process. I conclude by arguing that 'assessment dialogues' are a way forward to mitigate some of the mistrust or misconceptions that may be unwanted outcomes of the assessment process.

\section{Introduction}

A number of influential meta-analyses have confirmed that feedback is central to student learning (Black \& Wiliam, 1998; Hattie, Biggs \& Purdie, 1996; Hattie \& Jaeger, 1998). Ramsden (2003) argues that effective comments on students work represent one of the key characteristics of quality teaching. Hounsell (2003, p. 67) notes that "it has long been recognised, by researchers and practitioners alike, that feedback plays a decisive role in learning and development, within and beyond formal educational settings. We 
learn faster, and much more effectively, when we have a clear sense of how well we are doing and what we might need to do in order to improve”. In a discussion of the conditions under which assessment supports learning, Gibbs \& Simpson (2004) highlight the importance of feedback being understandable, timely and acted upon by students. Yorke (2003) argues that as well as the content of feedback, an awareness of the psychology of giving and receiving feedback is vitally important to student learning. Despite its importance, the literature on feedback reveals that students are often dissatisfied with the feedback they receive, in terms of lacking specific advice to improve (e.g. Higgins, Hartley \& Skelton, 2001), being difficult to interpret (Chanock, 2000) or having a potentially negative impact on students' self-perception and confidence (James, 2000).

The feedback I am referring to in this paper concerns responses to student assignments. It encompasses written annotations and comments on drafts or on finalised assignments, in addition to verbal dialogues prior to or after submission. Fleming (1999) argues that marking student scripts is one of the significant quality events in the lives of students and academics. Feedback of this nature can have multiple functions: advice for improvement of the current assignment; advice for improvement of future assignments; explaining or justifying a grade; an act by which the tutor demonstrates characteristics, such as expertise, diligence or authority; and the feedback function can also be little more than the fulfillment of a ritual which is part of academic life. Students, and even tutors themselves, may not be fully aware of which of these functions or which combination of them is being enacted. 
Tutors invest a lot of time in the kind of feedback discussed above, but what are the impacts on students and how might they relate to further learning? My pre-conceptions at the outset of this study were that students were mainly interested in and motivated by marks, and that they did not engage much with the written feedback we write on their papers. These conceptions were gleaned from my experiences with students and my interactions with colleagues. These included experiences when students did not bother to collect marked assignments (also noted by Mutch, 2003) and observations from colleagues that students "are only interested in the marks". This was reinforced by a comment in one of my classes from a student who during a discussion of the feedback process proclaimed, "if the mark is low, I won't go to collect the assignment". The data I collected have supported some of these positions but have also revealed some different perspectives and indicated that what some lecturers seem to think about their students may not be fully borne out.

Despite its central impact on learning, feedback is still relatively under-explored (Higgins, Hartley \& Skelton, 2002) and is a process which faces challenges, such as time, miscommunication and emotional barriers. The aim of the paper is to probe how students experience, understand and interpret the process of assignment feedback. The value of the paper lies in exemplifying the different perceptions of students and tutors, with regard to the assessment and feedback process. These differing viewpoints are represented as barriers that distort the potential for learning. An argument is made for 
'assessment dialogues' between tutors and students which seek to reduce the gap in perceptions.

\section{Framework for interpreting feedback}

The study is anchored conceptually by a framework for interpreting feedback adapted from Higgins (2000). I conceive of the student response to feedback being unpacked through three interlocking components, discourse, power and emotion which I discuss below.

Higgins (2000) argues that, "Many students are simply unable to understand feedback comments and interpret them correctly” (p. 1). Feedback is generally delivered in academic discourse which students may not have full access to. By discourse, I mean simply the language in which the tutor comments are encoded. The challenge of interpreting what is being said is compounded by the fact that discourses may vary across disciplines, across subjects or across tutors (Baynham, 2000). The use of discourse is a means by which tutors wittingly or unwittingly exert power over students. The ideology of universities demarcates novice students from authoritative academics and this is often reinforced by the role of correcting and judging scripts, rather than engaging in a debate on them (Ivanic, Clark \& Rimmershaw; 2000; Lea \& Street, 1998). There is a danger that the language of assessment feedback can be too final or as Boud (1995) puts it, "We judge too much and too powerfully, not realising the extent to which students experience our power over them” (p. 43). An aspect of power is potential bias, for example, Fleming (1999) indicates that tutors tend to mark up students who they perceive as 
approaching a task in a similar way to themselves or students with a previous track record of good grades. Scott (1995) argues that teachers also sometimes use grades to reward or punish students.

The assessment process is also a deeply emotional one (Boud, 1995). Students invest themselves and their time in assessment tasks and our response engages them on an emotional level or as Higgins, Hartley \& Skelton (2001) argue, "the student makes an emotional investment in an assignment and expects some 'return' on that investment" (p.272), for example, in terms of a grade or feedback. The impact of grades can have a negative impact on student engagement with feedback (Butler, 1988); grades engage the ego and associated emotional responses can distract students from the learning potential of feedback. Assignments are mainly a personal and individual activity, so if feedback is negative it can be threatening to a student's self-perception.

In sum, feedback is a social process in which elements, such as discourse, power and emotion impact on how messages can be interpreted. Important issues, under-explored in higher education and addressed by this paper are:

How do students perceive the feedback process?

To what extent are student perceptions different from tutors?

What are the implications for enhancing the feedback process? 


\section{Data collection and analysis}

The data for the study were collected within the specific context of higher education in Hong Kong. Respondents were Hong Kong Chinese students who do have particular characteristics, although the extent to which they differ from other students are sometimes misconceived or exaggerated (Kember, 2000). Fuller contextual background is not provided because the purpose of the paper is exploratory rather than attempting to advance universal claims. My main purpose is to generate analysis for further exploration. The intention is to elucidate the different conceptions that students have of feedback within the assessment process.

This paper draws on selected items from a large-scale questionnaire survey which explored various aspects of assessment and fine-grained qualitative data focused specifically on the issue of feedback. The questionnaire survey (reported in greater detail in Liu, 2004) was returned by 460 staff and 1740 students in the eight publicly funded universities in Hong Kong. This survey consisted of 36 items with scales in the Likert format asking students and tutors about various aspects of assessment purposes and assessment experiences; and one open-ended question which asked respondents to list problems to effective assessment practices. Two focus group interviews with university staff were also carried out to follow up on selected issues from the questionnaire. Using the Kuder-Richardson Formula 20, the reliability coefficients of the questionnaire were 0.82 for the student questionnaire and 0.80 for the tutor one (Liu, 2004), indicating that the questionnaires are reliable instruments which are likely to provide similar results if administered to another comparable sample. 
In order to probe more deeply into issues related to feedback raised by this questionnaire survey, qualitative data were also collected from $3^{\text {rd }}$ and $4^{\text {th }}$ year Bachelor of Education students from the main teacher education provider in Hong Kong; all respondents were Cantonese native-speakers, trainee English as a Foreign Language teachers. These data aimed to identify student viewpoints in more detail and for triangulation purposes three methods were used. Firstly, a small scale open-ended survey was completed (in English) by 52 students. This survey asked respondents to comment on effective or ineffective feedback, marking and grading processes of their lecturers and to make suggestions about the kind of feedback on assignments they found most useful.

Secondly, interview data were collected through semi-structured interviews (also in English) with 15 students in the same institution. Students were invited to participate in the light of my perception of their capacity to contribute insights to the research. Some informants were from the higher ability range of the cohort but I also included some students who had failed modules so as to probe their potentially contrasting viewpoints. The interviews focused on how students interpreted tutor feedback, its usefulness and how they responded in terms of comprehensibility of discourse, power relations and emotions. Parts of the later interviews were used to try to validate or invalidate findings from earlier interviews.

As a third means of qualitative data collection, I also asked a student research assistant to carry out six further interviews in Cantonese to ascertain whether she might uncover 
different insights. As assessment and feedback is quite a sensitive subject, it was considered that students might respond more frankly to her than to someone identified as an 'assessor', particularly with respect to issues such as emotions or lecturer bias.

Through coding and categorising of data, I identified themes which I interpreted as prominent. I then further analysed each theme and compared evidence from the different data sets. I tried to make sense of each theme by an iterative process of interpreting data, drawing tentative conclusions and returning to the raw data to seek evidence which confirmed or disconfirmed a particular line of thinking. Once I had developed a provisional argument from these themes, I interviewed five colleagues, selected on the basis of their ability to add insight to the interface between tutor and student perceptions. I reported to them aspects of the data which I found puzzling, surprising or interesting and asked them to elaborate their views or critique my interpretations. I used their perspectives to enhance the trustworthiness of the findings of the study.

Before proceeding some limitations of the paper should be acknowledged. The views represent those of a sample of Chinese students. The extent to which they may represent students in other contexts is debatable, but in view of the internationalisation of education, their perspectives merit consideration. The qualitative data clearly do not provide a basis for statistical generalisation but do enable student viewpoints to be aired and analysed. 


\section{Themes}

The discussion of the data is grouped into five themes developed from the analytic procedures described above: differing perceptions of students and lecturers, which is also an overarching theme of the paper; using feedback for improvement; comprehensibility of feedback and criteria; judgements, power relations and bias; and emotions, grades and failure. The first theme mainly draws on the large scale questionnaire survey data, whilst the remaining themes are based on the qualitative data. The themes are discussed separately for convenience of exposition but there is also considerable interplay between them with some points carrying relevance for more than one theme.

As the focus of the paper is differing perceptions of students and lecturers, perceptions are listed in concise form at the end of each relevant section. This device risks crudely summarising more complex issues, but is used to signpost key points in the discussion.

\section{Differing student and lecturer perceptions}

Feedback is a social process that may be interpreted in different ways and what constitutes feedback may also be disputed. The work of Gibbs and colleagues in the development of an Assessment Experience Questionnaire indicates for example, that whilst tutors may view oral comments as feedback, students may not recognise this form of feedback as much as written comments (Gibbs, Simpson \& MacDonald, 2003).

From the large scale questionnaire, tables 1 and 2 represent student and lecturer responses to the two items most explicitly related to feedback. The former item stated, 'Students 
were given detailed feedback that helped them improve their next assignments', the latter 'Feedback was followed by actions to improve student learning'. Staff and student respondents chose from the options, 'never', 'rarely', 'sometimes', 'often' and 'always'. A comparison of the tutor and student responses is represented in tables 1 and 2.

Table 1. Item: Students were given detailed feedback that helped them improve their next assignments

\begin{tabular}{ccccc}
\hline \multicolumn{5}{c}{ Tertiary tutors' views (\%) } \\
\hline Never & Rarely & Sometimes & Often & Always \\
& & & & \\
\hline 1.1 & 5.9 & 26.9 & 38.4 & 27.6 \\
\hline
\end{tabular}

\begin{tabular}{ccccc}
\hline \multicolumn{5}{c}{ Tertiary students' views (\%) } \\
\hline Never & Rarely & Sometimes & Often & Always \\
& & & & \\
\hline 12.1 & 40.3 & 35.0 & 10.6 & 2.0 \\
\hline
\end{tabular}

Table 2. Item: Feedback was followed by actions to improve student learning

\begin{tabular}{ccccc}
\hline \multicolumn{5}{c}{ Tertiary tutors' views (\%) } \\
\hline Never & Rarely & Sometimes & Often & Always \\
\hline 4.1 & 16.1 & 41.5 & 29.7 & 8.6 \\
\hline
\end{tabular}

\begin{tabular}{ccccc}
\hline \multicolumn{5}{c}{ Tertiary students' views (\%) } \\
\hline Never & Rarely & Sometimes & Often & Always \\
\hline 10.8 & 37.8 & 38.4 & 11.2 & 1.7 \\
\hline
\end{tabular}

For both questions, the data indicate that tutors perceived their feedback more positively than students did. This is not totally unexpected of course, but the difference in perceptions is quite striking. For example, 38.4\% of teachers thought students were often given detailed feedback which helped them improve their next assignment whilst 
only $10.6 \%$ of students responded in the same way. $\quad 37.8 \%$ of students felt that feedback was rarely followed by actions to improve student learning, as opposed to $16.1 \%$ of tutors. The results were statistically significant at a level of $\mathrm{p}<0.05$.

One of the tutors participating in the focus group discussion suggested that the student perceptions were probably more accurate because large class sizes and lack of time make it difficult for tutors to provide detailed feedback. Another tutor I interviewed felt that because students rarely received any feedback on examinations (other than a grade) this might account for their response, whilst tutors might think that the lack of feedback on exams was normal in view of standard institutional policies and respond to the item more in terms of assignments.

The open-ended question from this survey, which asked students to identify barriers to effective assessment, revealed that lack of feedback and lack of follow-up were mentioned as key problems in assessment, for example:

"I seldom know how to improve my next assessment because of the lack of comments or advice”

"Lack follow-up action and guidelines to correct mistakes made"

"Few comments on the assessment are given. Assessment seems like a means of giving a grade rather than helping students to learn”.

In response to the same open-ended question, tutors also saw aspects of the feedback process as representing one of the barriers to effective assessment practices, for example, 
insufficient time e.g. the amount of time needed to give effective feedback on written assignments (also exacerbated by large class sizes and other institutional constraints). Comments from tutors most directly related to feedback were:

"Students are interested in their marks and grades only. They are not interested to meet their tutors to get feedback on how to improve their learning” “Students don’t use feedback for learning purposes; they only use it to see how well they've done, especially compared to others” "Students are too worried about their grades".

Particularly poignant is the contrast between the student who felt that assessment was a means of grading rather than improving student learning, and lecturer complaints that students are too grade-oriented (see also the next section). This theme of differing perceptions of tutors and students reoccurs throughout the data.

Differing perception 1: Tutors believe that they are providing more detailed feedback than students do.

Differing perception 2: Tutors perceive their feedback to be more useful than students do. 


\section{Using feedback to improve}

The previous section has reported concerns from students about the usefulness of feedback based on the large scale questionnaire. This sub-section uses fine-grained data to provide additional perspectives to the theme of using feedback for improvement.

In interviews, several students stated unsurprisingly that they would look first at the mark awarded but also noted that they wanted to improve and were interested in tutors' responses to their work. Some of them also revisited their assignments over time, especially when a current assignment required a similar section to a previous one. As evidence of trying to improve by using previous work, one student stated that if she had done well in a certain area in one assignment, she would try to duplicate it in another. For example, she had obtained helpful advice from a tutor regarding citations and referencing, she then used this assignment as a kind of template for future attempts at referencing. Another student had the habit of re-reading her old assignments to monitor her improvement. When reading her assignments from two years previously, she gained confidence by noticing how much she had improved.

Although students wanted to learn from feedback, they often found this difficult. A number of students commented that they could not improve much from the lecturers' comments because they were specific to a particular assignment and so did not provide support to do better in another assignment for a different module. This prompted several students to suggest that comments could be more profitably directed on generic issues, for example, "Referencing and citations are common to most assignments, so it is 
useful to get feedback on these”. This reinforces a point made by Knight \& Yorke (2003) that "although many teachers give a lot of feedback on specifics, it is general feedback that has the greater power to stimulate learning” (p.33). Such feedback has the potential to 'feedforward', into future tasks rather than back to completed assignments.

Tutor comments on drafts or outlines were viewed by students as a particularly important source of feedback or feedforward because they provided an immediate opportunity to act on advice. Several students argued that feedback on drafts was much more useful than comments on the final version; and if a tutor had spent time commenting on drafts, they considered it reasonable for much briefer feedback to be written on the final version. Somewhat surprisingly to me, when offered such a service a minority of interviewees did not always avail themselves of this opportunity to collect feedback on a draft. Sometimes they explained this as poor time management, but other reasons were offered, for example, "Sometimes we worry that the lecturer may be judging us on the draft, we think it is better not to attend a consultation than to let the tutor see that you haven't prepared much”. Fairness was also raised with respect to drafts with dissatisfaction expressed when some students were believed to have received more support than others.

Overall, students obviously viewed grades as highly important, and whilst some seemed predominantly focused on this aspect, most of the students I interviewed were interested in more than the mark. They wanted to improve and engage with tutors' responses to their work, but had difficulty in translating comments into future improvements in different assignments. If tutors had time or were able to organise a module so that 
comments on work in progress could be provided, this was perceived as a particularly valuable form of feedback.

Differing perception 3: The perception of some tutors that students are only interested in their grades is brought into question. The balance of student focus on grades and/or future improvement remains unclear.

\section{Comprehensibility of feedback and criteria}

If they are to engage successfully with comments and assessment criteria, students need as a starting point to be able to access the discourses in which this feedback is embedded. The data show that some students perceived that they could interpret tutors' comments reasonably well, whilst others found it harder to decipher handwriting or catch what the lecturer meant. For example, one student commented, "Sometimes their comments are not comprehensive enough, once a lecturer wrote 'you need to elaborate more' but I had no idea what more I could say”. When they did not understand a comment on a final assignment, a few students claimed that they would approach the tutor for elaboration or send an e-mail query, although a majority of interviewees would not. One student expressed it as follows:

"I try to understand it, but I seldom understand the written feedback on the marked assignments. Sometimes I get frustrated if I can’t read their writing or understand what they are saying”. 
Although I felt that students were not particularly sensitive to the workload implications for staff, they often suggested that consultations would be valuable, for example, "if the tutors can talk about the assignment with the students after marking, I think it is more effective for our learning”. But when asked if they took the initiative to approach lecturers, they invariably said that they did not. A variation on the consultation idea was a student suggestion that a lecturer could organise a whole-class optional tutorial of about 20-30 minutes for general feedback on the assignment. She believed that about half of her classmates would attend this kind of meeting and it would be more human and interactive than an e-mail highlighting strengths and weaknesses, although the latter would also be quite useful.

The assessment criteria represented another form of discourse which could be a challenge for students to interpret. When asked about the criteria, one student responded as follows:

"We always get a copy of the criteria, usually in the first session. Usually the tutors don't make any explanation, they just give it to us. I can usually understand the criteria but not always".

When asked how she utilised the criteria, she responded as follows:

"I look at the criteria for grade A and highlight the points which seem relevant. I focus on the A grade because I think if I aim for A, I may get B or B+, but if I aim for B, I might get C+”. 
A second student outlined her perspective as follows:

"Sometimes the criteria are not detailed enough or I am not really sure what it actually means in terms of doing the assignment, so I try to guess what the lecturers are looking for from what they say in class”.

This strategy struck me as having considerable danger for misinterpretation.

A third student was unable to distinguish clearly between different sets of criteria used for different modules and confessed to having a limited understanding of what the criteria represented and how this was converted into a grade.

Overall, assessment criteria and the unpacking of its discourse seemed to represent a barrier to student understanding of required standards. Tutors themselves also believed this to be the case, for example:

“I don’t think the students really understand the assessment criteria. I don't have time to explain criteria in class, but I often give them one or two samples of good student work related to the module content so that they have an idea of the standards required”.

The five tutors I interviewed did not report carrying out activities which supported students' understanding of criteria (cf. Rust, Price \& O’Donovan, 2003). An implication is that tutors need to do more to enhance students' understanding of criteria. 
Similar perception 1: Both tutors and students seemed to be in agreement that students found it difficult to decode criteria.

Judgements, power relations and bias

Helpful assignment feedback requires judgements that are trustworthy and perceived as fair by students. A number of students in my small-scale survey felt that some lecturers were biased or subjective, for example:

"Sometimes the lecturers are subjective, what they want us to do is different from the criteria for the assignment”

"If the lecturer thinks that the student is hard-working or lazy then this will influence the mark"

"Sometimes we feel that the more consultations you have with the lecturer, the higher the grade you get”.

Generally however, the majority of students I interviewed seemed to believe that there were not major problems in terms of tutor bias, but when there were multiple tutors for a module, problems were accentuated:

"When there is one lecturer for a module, it is reasonably fair, but when there are multiple groups, it is less fair. We know the lecturers who are 'strict' or 'lenient', students will discuss amongst themselves, so we will try and get into the class of the more generous marker". 
Students had some awareness of double-marking and moderation procedures, but demonstrated inconsistent understanding of how these processes operated. One student, for example, thought that every assignment (rather than a sample) was double-marked and when I explained the reality, she expressed less confidence in the fairness of marking. Another more critical student understood the principles of selective double-marking but was not convinced it operated well in practice. When asked if students would ever try to negotiate with a strict marker, she replied, "no, we dare not do so", illustrative of the relationships of authority between students and tutors. Tutors, on the other hand, did report instances of students trying to negotiate over a failed assignment, not to change the mark but to plead for a re-submission of the assignment, rather than a re-sit examination or re-taking the entire module, as required by the university regulations.

When students were interviewed by my student research assistant it was more common for them to allege tutor bias. Bias was perceived in a number of different ways:

- Favourite students, such as those who were attentive or active in class

- Students who went to the tutor's office to ask questions or consult with the tutor (students thought tutors appreciated this kind of behaviour as it showed sincerity and commitment)

- Preference for students who followed their advice or chose the kind of topics or approaches favoured by the lecturer.

I had a hunch that students who received high grades might find lecturers fair and objective, whilst students who obtained low marks or failed a module might allege bias 
and subjectivity. Although there were interviews in which this phenomenon seemed to occur, one student, who had previously failed several modules, did not attempt to shift blame onto the lecturers:

"I consulted with the tutors to find out why I failed, they were patient and sympathetic. I thought the failure grades were fair. Two years later, I read the assignment again and I thought it was rubbish”.

Of surprise to me was the fact that the student would revisit an old assignment in this way, particularly in a case when it was a failed one.

From my viewpoint as a tutor, some of the student allegations of bias were not convincing. For example, it seemed to me that if a student performs well in class and subsequently gets a high mark, students may jump to an inaccurate conclusion that the class performance contributed to the grade. Yet that they might reach that conclusion without having seen the relevant assignment reinforces the point that perceptions loom large in the assessment process. In this as in other aspects of the findings, it was unclear what were merely perceptions and what was closer to reality.

One of the tutors I interviewed believed that students were unable to distinguish between general ability and performance in a specific assignment. In other words, if a student found a classmate generally weaker than herself receiving a higher mark, she might suspect bias when the cause might be student under- or over-achievement on a particular piece of work. Another tutor noted that students have difficulty in distinguishing between the amount of time and effort they have invested, and the quality of the work. 
Similarly, a third tutor suggested that the main reason that students alleged bias was because of their lack of ability to self-evaluate. Without sufficient means to distinguish accurately their achievements in different assignments, students may assume that their variation in grades is a product of the tutor rather than their own performance. Maclellan (2001) argues that unless students are monitoring and regulating the quality of their own learning, feedback in itself, regardless of the degree of detail, is unlikely to generate improvement in learning.

Differing perception 4: Tutors believe that their marking is fair, whilst students had mixed feelings about the fairness of the grading.

\section{Emotions, grades and failure}

The asymmetrical power relations inherent in the assessment process risk invoking negative emotions which may form a barrier to learning from feedback. One person's helpful suggestion may be another person's judgemental criticism. The data reveal different aspects of the emotional impact of assessment and feedback.

"If the feedback is not so good, first I may feel depressed, but quite soon I may adjust myself to see how to do it better next time”

"If I get a low mark, I like to try and forget about the assignment for some time because if I read it again it will make me unhappy”

"When I check to see the mark [on the notice-board], I feel pressurised. If the grade is okay, the pressure is released”. 
The student referred to in the previous section who had failed a number of modules mentioned the impact these unpleasant experiences had on her feelings towards assessment: "I felt sad and scared when I got a failure grade. Even now, when I hand in the assignment, I feel pressurised and afraid that I will fail”.

Amongst the students I interviewed, there was also sensitivity towards the emotional impact on other students:

“If I get a high mark, I don’t want my friends to know, they may feel sad if their mark is lower"

"If I go to the notice-board to find out my mark, I prefer to go alone, because if you check the mark with a friend, one of you may have hard feelings or you may need to comfort your friend”.

Tutors confirmed the emotional burdens of assessment on both themselves and students. They all had tales to recount of distraught students who had done badly in their modules. A recurrent theme in these narratives was of students not taking responsibility for their performance and implicitly blaming the lecturer rather than themselves (cf. perceptions of bias discussed earlier).

The emotional side of assessment is worth further investigation. As a starting point, it seems likely that better students are more receptive to feedback because of their greater confidence and better understanding of what good performance entails; for the weaker student feedback carries more risk of being discouraging and/or misunderstood. An 
ability to provide pertinent feedback that does not impact negatively on student egos seems to be a useful skill for tutors to develop. For example, feedback that can be provided without a grade or before a mark is awarded (e.g. Carless, 2002) helps to reduce the potentially negative impact of the award of a grade and so facilitate students' engagement with the feedback. Disengaging feedback from grades seems a useful strategy for improvement as increasingly discussed in the literature related to assessment for learning in schools (e.g. Black et al., 2003).

Similar perception 2: Both tutors and students seem cognisant of the emotional aspects of assessment.

\section{Conclusions and implications}

The findings, albeit not particularly surprising, document the views of a sample of students in Hong Kong. What the large-scale questionnaire have revealed is that students (and to some extent) lecturers perceive that lack of useful feedback is a problem in the assessment process and that tutors believe that their feedback is more useful than students do, reinforcing an earlier Scottish study (Maclellan, 2001). The more fine-grained data from a teacher education institution have elaborated students' responses to themes related to the framework of discourse, power and emotions.

A recurring finding was that students had different perspectives to staff on elements of the assessment and feedback process. Four differing perceptions have been discussed: the amount of detail of feedback; the usefulness of feedback; the extent to which students 
are only interested in grades; and the fairness of marking procedures. These perceptions represent a key challenge to enhancing assessment and feedback practices. Staff and students have different positions, roles and aims, and the scope for narrowing variation in assumptions may be limited. I suggest that a step in reducing misconceptions or differing perceptions can be through 'Assessment dialogues' between tutors and students - discussions related to the assessment process as a general concept, but not related to the specifics of subject matter or what students need to do for a particular assignment. Given the centrality of assessment to learning, students need to learn about assessment in the same way that they engage with subject content. Assessment dialogues can help students to clarify 'the rules of the game', the assumptions known to lecturers but less transparent to students. For example, if students are to develop the kind of self-monitoring skills required for lifelong learning, they need to be starting to develop conceptions of standards comparable to those of their lecturers (Boud \& Falchikov, forthcoming; Sadler, 1989, 2002). Demystifying the assessment process can make a contribution to such student processes of engaging with required standards.

The content of assessment dialogues might seem obvious or second nature to tutors, but issues may be misinterpreted by students. It is precisely these tacit assumptions that are automatic to tutors that need to be aired with students in an attempt to clarify the assessment process. Some of the areas in which assessment dialogues might be useful include:

- Unpacking assessment criteria or involving students in generating or applying criteria 
- Reminding students that grades for assignments are awarded on the basis of these criteria and not other factors, such as performance in class, attendance, appearance, gender or ethnicity; low grades do not imply a rejection of the student; and hard work does not guarantee a high mark

- The marking process itself; what tutors hope to achieve through their written annotations and how students might utilise them

- Second marking or moderation procedures and possibly the role of boards of examiners and external examiners.

Assessment dialogues might simply involve tutors being more explicit about assessment procedures and being more open to student questions. Assessment is usually the issue which generates most student attention and inquiries (Reynolds \& Trehan, 2000).

Given the impact of assessment on student success or failure in the university setting, assessment dialogues have a role to play in reinforcing what is going on at different stages in the assessment process, from assessment design to summative feedback. Assessment is too important for us to assume that students are on the same wavelength as we are. Failure to find time for such dialogues may engender negative consequences such as student dissatisfaction, underachievement or even impact negatively on retention (Yorke, 2001).

As a final word, I found that assessment was a topic that students were very willing to discuss. Because assessment is so central to their university experience, it was something that they had a lot to say about. One student respondent commented: "no 
tutor has ever asked us what kind of feedback we would like. This is an important topic, please share your findings with other lecturers”.

Correspondence: David Carless, English Department, Hong Kong Institute of Education, 10 Lo Ping Road, Tai Po, Hong Kong;

e-mail:dcarless@ied.edu.hk

\section{REFERENCES}

Baynham, M. (2000) Academic writing in new and emergent discipline areas, in: M. Lea \& B. Stierer (Eds) New Contexts for Student Writing in Higher Education (Maidenhead, Open University Press and SRHE).

Black, P., \& Wiliam, D. (1998) Assessment and classroom learning, Assessment in Education, 5(1), 7-74.

Black, P., Harrison, C., Lee, C., Marshall, B., \& Wiliam, D. (2003) Assessment for learning: Putting it into practice (Maidenhead, Open University Press).

Boud, D. (1995) Assessment and learning: contradictory or complementary? in: P. Knight (Ed) Assessment and Learning in Higher Education (London, Kogan Page).

Boud, D. \& Falchikov, N. (forthcoming) Aligning assessment with long-term learning, Assessment and Evaluation in Higher Education.

Butler, R. (1988) Enhancing and undermining intrinsic motivation; the effects of task-involving and ego-involving evaluation on interest and performance. British journal of educational psychology 58, 1-14. 
Carless, D. (2002) The 'mini-viva' as a tool to enhance assessment for learning. Assessment and Evaluation in Higher Education, 27(4), 353-363.

Chanock, K. (2000) Comments on essays: do students understand what tutors write? Teaching in higher education, 5, 1, 95-105.

Fleming, N. (1999) Biases in marking students’ written work: quality? in: S. Brown \& A. Glasner (Eds) Assessment Matters in Higher Education: choosing and using diverse approaches (Buckingham, SRHE and Open University).

Gibbs, G. \& Simpson, C. (2004) Conditions under which assessment supports students’ learning, Learning and teaching in higher education, 1, 3-31. Available online: http://www.glos.ac.uk/departments/ clt/lathe/issue1/index.cfm

Gibbs, G., Simpson, C. \& Macdonald, R. (2003) Improving Student Learning through Changing Assessment - a conceptual and practical framework, paper presented to EARLI conference, Padova, August 26-30.

Hattie, J., Biggs, J. \& Purdie, N. (1996) Effects of learning skills intervention on student learning: a meta-analysis, International Journal of Educational Research, 11, 187-212.

Hattie, J. \& Jaeger, R. (1998) Assessment and classroom learning: a deductive approach, Assessment in Education, 5(1), 111-122.

Higgins, R. (2000) “Be more critical”: rethinking assessment feedback, paper presented to British Educational Research Association Conference, Cardiff University, 7-10 September. Available http://www.leeds.ac.uk/educol/documents/00001548.htm

Higgins, R., Hartley, P., \& Skelton, A. (2001) Getting the message across: the problem of communicating assessment feedback, Teaching in Higher Education, 6 (2), 269-274. 
Higgins, R., Hartley, P., \& Skelton, A. (2002) The conscientious consumer: reconsidering the role of assessment feedback in student learning, Studies in Higher Education, 27(1), 53-64.

Hounsell, D. (2003) Student feedback, learning and development, in: M. Slowey \& D. Watson (Eds), Higher Education and the Lifecourse (Maidenhead, SRHE and Open University Press).

Ivanič, R., Clark, R. \& Rimmershaw, R. (2000) What am I supposed to make of this? The messages conveyed to students by tutors' written comments, in: M. R. Lea \& B. Stierer (Eds) Student Writing in Higher Education: new contexts (Buckingham, Open University Press).

James, D. (2000) Making the graduate: perspectives on student experience of assessment in higher education, in: A. Filer (Ed), Assessment: social practice and social product (London and New York, Routledge / Falmer).

Kember, D. (2000) Misconceptions about the learning approaches, motivation and study practices of Asian students, Higher Education, 40, 99-121.

Knight, P. \& Yorke, M. (2003) Assessment, Learning and Employability (Maidenhead, SRHE and Open University Press).

Lea, M., \& Street, B. (1998) Student writing in higher education: an academic literacies approach, Studies in Higher Education, 23 (2), 157-172.

Liu, N.F. (2004) Hong Kong tertiary teachers' and students' perceptions of assessment purposes and practices, paper presented to Learning-oriented assessment conference, Hong Kong Institute of Education, 11 June. 
Maclellan, E. (2001) Assessment for learning: the differing perceptions of tutors and students, Assessment and Evaluation in Higher Education, 26(4), pp. 307-318.

Mutch, A. (2003) Exploring the practice of feedback to students, Active Learning in Higher Education, 4(1), 24-38.

Ramsden, P. (2003) Learning to Teach in Higher Education, 5th edn (London, Routledge Falmer).

Reynolds, M. \& Trehan, K. (2000) Assessment: a critical perspective, Studies in Higher Education, 25(3), 267-278.

Rust, C., Price, M. \& O’Donovan, B. (2003) Improving students’ learning by developing their understanding of assessment criteria and processes, Assessment and Evaluation in Higher Education, 28(2), 147-164.

Sadler, D. (1989) Formative assessment and the design of instructional systems. Instructional Science 18, 119-144.

Sadler, R. (2002) Ah! ... So that's 'quality’, in: P. Schwartz \& G. Webb (Eds), Assessment: Case studies, experience and practice from higher education, (London, Kogan Page,).

Scott, E-L. (1995) 'Mokita' The truth that everyone knows but nobody talks about: bias in grading, Teaching English in the Two Year College, 22(3), 211-16.

Yorke, M. (2001) Formative assessment and its relevance to retention, Higher Education Research and Development, 20(2), 115-126.

Yorke, M. (2003) Formative assessment in higher education: moves towards theory and the enhancement of pedagogic practice, Higher Education, 45, 477-501. 